\title{
COMPRENSIÓN COMO PARTICIPACIÓN: DIALÉCTICA ENTRE LA PARTICULARIDAD Y LA GENERALIDAD EN LA HERMENÉUTICA DE GADAMER
}

\author{
Maria del Rosario Gazmuri Barros ${ }^{1}$
}

Resumen: El presente artículo se propone exponer la noción gadameriana de comprensión como participación, con el objetivo de mostrar cómo se produce el juego entre la particularidad de la interpretación y la pretensión de generalidad supuesta en el hecho de que toda interpretación pertenece a una tradición. A partir de la perspectiva ganada por la ontología de la obra de arte, específicamente la obra de arte teatral, el presente artículo indagará en las nociones centrales de la hermenéutica filosófica de Gadamer. En primer lugar, las nociones de representación y mediación, cruciales para comprender qué es la comprensión para nuestro autor. En segundo lugar, se presentará el problema de la temporalidad de la representación, cara a, en tercer lugar, exponer qué significa, en sentido propio, interpretación en la hermenéutica gadameriana. Por último, se abordará la cuestión de la tarea hermenéutica en medio de la historicidad, en la que concurren la particularidad y la generalidad.

Palabras clave: Interpretación. Obra de arte. Representación. Temporalidad. Historicidad. Participación. Comprensión.

\section{INTRODUCCIÓN}

Toda la obra de Gadamer transita en el esfuerzo constante por recuperar qué es propiamente la comprensión. Su propio proyecto bebe del de su maestro, Heidegger, y, por esto, lo que impulsa su reflexión es también la crítica a una concepción de verdad demasiado estrecha para dar fe del mundo y de la racionalidad humana, una crítica que busca, por tanto, recuperar la experiencia originaria de la verdad. Como acertadamente indica Grondin (2003, p.18), la recuperación que busca Gadamer de las experiencias de verdad que han sido encubiertas por el monopolio del método, lleva consigo el cuestionamiento de dos presupuestos: la búsqueda de un saber que sea

${ }_{1}^{1}$ Profesor Asistente en Pontificia Universidad Católica de Chile, Santiago - Chile. (D) https://orcid. org/0000-0002-9999-4521 E-mail: mdgazmur@uc.cl

https://doi.org/10.1590/0101-3173.2021.v44n1.19.p265

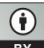

This is an open-access article distributed under the terms of the Creative Commons Attribution License. 
absolutamente claro y distinto y la hipótesis de que la clave de ese saber se encuentra en la reflexividad del pensamiento que se piensa a sí mismo. La búsqueda gadameriana irá en la dirección de abrir la noción de verdad desde experiencias de verdad no metódicas, para descubrirnos el comprender como acontecer de la verdad. En Verdad y Método, Gadamer se centra en la ontología de la obra de arte, ontología que resulta fundamental para comprender su noción de comprensión.

El fenómeno de la comprensión no solo atraviesa todas las referencias humanas al mundo, sino que también tiene validez propia dentro de la ciencia y se resiste a cualquier intento de transformarlo en un método científico. La presente investigación toma pie en esta resistencia, que se afirma dentro de la ciencia moderna frente a la pretensión de universalidad de la metodología científica. (GADAMER, 2005, p. 23-24).

Desde la ontología de la obra de arte, el autor pretende mostrar la estrechez de la noción de verdad y conocimiento que se ha establecido a partir de la modernidad. Una vez realizada esta tarea, la segunda parte de esta obra Gadamer la dedica, desde la apertura ganada de la noción de comprensión por la ontología de la obra de arte, a la expansión de la cuestión de la verdad a la comprensión de las ciencias del espíritu. Es aquí donde nuestro autor pone las bases de su teoría hermenéutica. Por último, en la tercera parte, Gadamer se aboca a la caracterización del papel que juega el lenguaje en la comprensión, que para él es siempre interpretación. El análisis que hace del lenguaje es deudor también del análisis que previamente realiza sobre la obra de arte y la estructura de la comprensión. Sólo desde la idea de comprensión que delinea en la primera y segunda parte de la obra se entiende la conclusión a la que llega en la tercera parte: toda comprensión es interpretación, y toda interpretación, necesariamente, se realiza en el medio del lenguaje. El modelo del lenguaje y de la estructura hermenéutica sigue, por tanto, el modelo de la obra de arte, a partir del cual pretende mostrar cuanto de acontecer hay en todo comprender, lo que implicaría un paradigma de comprensión muy diferente al de ésta como dominio, que es como se la ha erigido desde la modernidad.

En el presente trabajo, nos centraremos, por tanto, en la obra de arte, para esclarecer las bases de la hermenéutica que Gadamer propone. Con este fin, abordaremos el análisis de un tipo de obra de arte en específico: la obra de arte teatral. La descripción de este tipo de obra resulta especialmente elocuente en vistas a la dilucidación de la cuestión de qué significa que la interpretación 
sea representación, en tanto el teatro es un ejemplo que grafica esta noción. En el lenguaje cotidiano hablamos de la representación teatral y de que los actores interpretan un papel. Desde esta constatación, Gadamer profundizará en la noción de interpretación, en vistas de mostrar que toda comprensión es interpretación y que esta posee la estructura de la participación. Con este fin, mostraremos algunas nociones centrales para la cuestión de la interpretación. En primer lugar, desarrollaremos la noción de representación para luego describir qué significa la mediación de la representación. En segundo lugar, nos focalizaremos en la cuestión de la temporalidad de dicha representación y las consecuencias de ésta de cara a la temporalidad de toda interpretación. Por último, y desde los horizontes abiertos por la ontología de la obra de arte, expondremos el problema de la historicidad de toda comprensión para concluir con la descripción de la experiencia hermenéutica.

Tal como decíamos, la obra de Gadamer bebe de la de Heidegger en su inspiración. Ahora bien, su propio proyecto comienza su camino en el como apofántico de Heidegger. Es decir, si para Heidegger el primer acceso comprensivo del Dasein al mundo, la primera apertura se da en el trato con los entes a la mano, cuando Gadamer habla de comprensión comienza en el segundo estrato heideggeriano: en la perspectiva del como. Esta decisión, legítima cara a las pretensiones de su propio proyecto, tiene, sin embargo, algunas consecuencias problemáticas, según veremos a lo largo del desarrollo de este trabajo.

\section{LA ONTOLOGÍA DE LA OBRA DE ARTE: LA REPRESENTACIÓN TEATRAL}

Para Gadamer, la noción central que le revelará el sentido último de la hermenéutica, y de toda comprensión, es el concepto de Darstellung, de exhibición o mostración de la verdad. Para comenzar con la exposición de la noción de Darstellung, nuestro autor acudirá a una metáfora: el juego. La primera intención de Gadamer al acudir a esta idea es romper con el paradigma sujeto - objeto, puesto que, en el juego, evidentemente, no se puede sostener esta distinción: para que el juego se realice, el jugador tiene que dejarse llevar por su juego. El juego no son las reglas ni los instrumentos del juego (el objeto), sino la puesta en marcha de éste por el jugador (sujeto). Por esto se puede decir que el modo de ser de la obra de arte es como el del juego, en el sentido de que, así como en la obra de arte, en el juego solo se cumple su objetivo propio cuando el jugador se abandona del todo a él. Hay una primacía del juego 
frente a la conciencia del jugador, aunque esto no significa que el jugador sea meramente pasivo: él tiene que conocer el juego, y este conocimiento no es nunca meramente teórico: requiere una praxis. El dominio, en la experiencia del juego, no lo tiene el que juega, sino el juego mismo. Solo cuando el jugador se deja llevar por el juego, se puede decir que lo domina. Ahora bien, para Gadamer, la esencia del juego se realiza de modo pleno cuando este tiene un espectador, para quien el juego se exhibe; cuando el juego es representación. De hecho, un buen juego es el que ha alcanzado tal arte, que se exhibe ante otros. Esto sucede de modo natural: cuando hay expertos jugadores se forma en torno a ellos un grupo de observadores; basta pensar en el fenómeno del fútbol o en los juegos olímpicos: todo juego busca alcanzar la categoría necesaria para merecer ser exhibido. Esto sucede también en el juego cultual, en el que el rito se realiza por la participación de los jugadores, aunque no se limita a esto. El espectador y el juego son entonces los que se entrelazan en pos de la realización del juego mismo. Es lo que sucede en cualquier obra de arte: el espectador solo comprende la obra cuando se deja llevar por ella, por lo que ella propone. Para graficar esta cuestión, y mostrar sus consecuencias, Gadamer acude a la obra de arte teatral.

La obra de arte teatral es como el juego: es representación y ella se representa para el espectador, sin el cual no se realiza la esencia misma de la obra. De hecho, la obra escrita está concebida para ser representada, y es la puesta en escena la que lleva al texto a su plena realización. Este hecho determina que lo que se juega en la representación teatral sea esencial, lo que saben tanto los actores y el director, como los espectadores. Y solo se exhibe la representación cuando esta ha alcanzado un nivel adecuado. En este sentido la presencia del público determina la realización de la representación. Por otra parte, tanto quien asiste como quien actúa sabe que debe comportarse frente a la obra de un modo diferente al modo como lo hace en la praxis cotidiana: el espectador no interviene en la representación como intervendría, por ejemplo, si esas mismas acciones las estuviese presenciando en la vida cotidiana. Esto implica, como sucede también en el juego, una desconexión de los nexos causales de la vida diaria: esta desconexión posibilita el abandono del espectador en manos de lo representado, permite entregarse a la seriedad de lo que se pone por obra, condición imprescindible para que haya una experiencia de comprensión.

Por otra parte, la representación teatral no busca otra meta en esa actuación que la manifestación de la obra teatral escrita, con la mayor perfección 
esperable. El fin no es externo a la obra misma: es ella misma en su esencial mostración. Y esta meta es posible no solo cuando cada actor conoce su papel, la obra escrita, y se entrega de lleno a ella, sino también cuando el espectador tiene una experiencia previa con ella, con la obra y/o con el arte teatral mismo: la apreciación de la obra no depende solo de que el espectador comprenda los diálogos, de la mera comprensión teórica o temática de lo que allí se dice, sino que hay un cierto trato con el teatro que lleva a formar el criterio para gozar de la obra, como ocurre también, de modo mucho más evidente, en el caso de la representación musical. Es lo que ocurre en la tragedia griega, para la que el efecto en el espectador es parte esencial.

[...] imitación de una acción de carácter elevado y completa, dotada de una cierta extensión, en lenguaje agradable, llena de bellezas de una especie particular según diversas partes, imitación que ha sido hecha o lo es por los personajes y no por medio de una narración, la cual, moviendo a compasión (éleos) y temor (phóbos), obra en el espectador la purificación propia (catarsis) de estos estados emotivos. (ARISTÓTELES, Poética, 1449b, 20-25)

Ahora bien, esta participación del espectador no es una acción que interfiera en la trama presentada por la obra trágica: él solo puede aceptar los acontecimientos. Sin embargo, los hechos presentados están ahí para lograr el efecto en el espectador. La participación, por tanto, lo es en el sentido más estricto de la palabra. No sólo se le exhibe al espectador la verdad mostrándole un mundo, que remite a o abre un nuevo sentido a su mundo, sino que él mismo participa de ese mundo abierto y comprende su verdad desde su propia experiencia frente a la obra.

\subsection{REPRESENTACIÓN Y MEDIACIÓN}

Desde el análisis de la representación teatral se ha delineado la noción de representación (Darstellung), que será crucial para comprender qué es la interpretación para Gadamer. La cuestión que queda por delimitar es qué es la representación en sí misma, pues para nuestro autor todo arte es representación. Desde la obra de teatro, esta noción cobra voz y movimiento, y nos lleva a comprender que siempre es representación de algo: de un juego, de un texto, de una tragedia. La representación es aquello que se pone ante nuestra mirada, y con ello hace presente algo otro. Ahora bien, como bien muestra el ejemplo del teatro, lo que importa no es tal o cual representación 
de la obra, del texto en cuestión, sino el texto mismo; a la vez, el texto solo está de manera plena en la representación. Lo vinculante es la obra, pero esta a su vez se manifiesta solo en la representación o interpretación. La obra de arte " $[\ldots]$ no autoriza a interpretarla de cualquier forma, sino que, con toda su apertura y toda la amplitud de juego de las posibilidades de interpretarla, permite establecer una pauta de lo que es adecuado; es más, incluso la exige." (GADAMER, 2011, p. 56).

Para Gadamer esta cuestión será crucial: la obra solo está ahí en la representación. A la vez, una misma obra permite una pluralidad de representaciones, pero es ella la que permanece y se destaca en cada una. En cuanto la dirección intencional no sea la obra misma, sino la representación, esa mediación fracasa como tal. Siempre que haya una dirección que apunte a algo que no sea el significado de la obra, la experiencia de sentido se quiebra, pues se imposibilita la participación en la obra misma. Esto es posible sólo cuando la mediación fracasa y, por tanto, deja de ser mediación, se autonomiza. Por esto, el objetivo de la representación es lo que Gadamer denomina mediación total, es decir, que lo que media lo hace de manera tal que se cancela a sí misma como mediación y presenta la cuestión en sí misma. Cuando la mediación no es total, cuando la representación no desaparece como tal en pos de la manifestación de la esencia, no hay realmente mediación alguna. Una mala interpretación de una obra no puede llegar a ser mediación total justamente porque ella aparece como algo diferente a la obra misma: ella se destaca como mediación e impide, de este modo, el acceso hacia la significación de la obra misma. Es lo que sucede también cuando un actor destaca en sí mismo y no por su papel que cumple con maestría. La atención, en estos casos, se centra en una persona, no en lo que se representa. El todo significativo que la obra tiene queda diezmado por la dirección hacia la persona que actúa. Por esto, para que haya realmente representación tiene que suspenderse la identidad de quienes actúan. Como en el juego de los niños: justamente lo imprescindible es no ser reconocido tras el disfraz, desaparecer en pos del papel que se juega en la representación.

Ahora bien, los actores de la obra realizan la exhibición de un modo peculiar: en la representación siempre hay algo de exageración, algo que da relieve, un como que nos abre un nuevo panorama de lo representado. Siempre quien actúa pone el acento en unas características de sus personajes o en algunas palabras de su parlamento. Cuando se quiere mostrar, hay que exagerar: así, el personaje que tiene que hacer de cómico, exagera la risa, y el que tiene 
que mostrarse vulnerable, destaca su pesar. De este modo se asegura de dar el acento que quiere a su personaje, y de ser comprendido en su interpretación. Este desborde es propio de todo arte, en tanto es interpretación. El arte teatral, por tanto, se juega sobre estos dos polos: por una parte, tiene que mostrar la obra, sin destacar como representación de ella, y por otra, para lograrlo, quienes la llevan a cabo tienen que marcar ciertos acentos. Pero esto último no atenta contra el hecho de que la representación medie de modo total, sino que, muy por el contrario, en este modo de mediar está el arte de la representación.

Desde esta perspectiva, la mediación que es cada representación del texto teatral no es mera imitación, como tampoco lo son las sucesivas representaciones respecto de la representación inicial: en cada una de ellas hay un como particular, un modo de poner los acentos, de marcar los caracteres, que no está presente en la otra. Y en cada una de ellas se cumple, sin embargo, ser una manifestación del texto mismo, hasta tal punto que, como ya hemos dicho, es la obra misma la que se hace presente. El que representa un papel en la obra, es, desde esta perspectiva, libre, a la vez que se deja determinar por la obra que representa. Las diversas interpretaciones no eliminan, por tanto, la vinculatividad de la obra misma. La interpretación, cuando lo es verdaderamente, no se guía por un acto interpretador precedente, sino por la obra misma.

En cuanto que no son mera repetición sino verdadero "poner de relieve", hay en ellas al mismo tiempo una referencia al espectador. Contienen en sí una referencia a todo aquél para quien pueda darse la representación. Se puede ir aún más lejos: la representación de la esencia es tan poco mera imitación que es necesariamente mostrativa. El que reproduce algo está obligado a dejar unas cosas y destacar otras. Al estar mostrando tiene que exagerar, lo quiera o no. Y en este sentido se produce una desproporción óntica insuperable entre lo que "es como" algo y aquello a lo que quiere asemejarse. (GADAMER, 2005, p. 159).

Esta desproporción o distancia óntica es central para Gadamer: ella muestra que nunca hay una simple adecuación entre lo que la representación muestra y la obra a la que hace referencia. Sin embargo, solo por esta desproporción, el original puede llevarse a cabo, puede mostrarse. Es decir, esta desproporción tiene un valor cognitivo de primer orden. Esta transformación óntica de lo representado en la representación es a lo que Gadamer denomina interpretación, y es lo que define como esencia de la comprensión. Toda comprensión es interpretación. 
Ahora bien, las consecuencias de esta transformación óntica serán, en la obra de Gadamer, conflictivas, según veremos.

\subsection{LA TEMPORALIDAD DE LA REPRESENTACIÓN}

Desde las perspectivas entregadas por el análisis de la representación y de la mediación total que se produce, surge la cuestión de la temporalidad de la obra. Por una parte, pareciera que toda obra de arte pertenece a un presente eterno, pues siempre puede actualizarse, a pesar de que su origen sea lejano. Por otra parte, si solo hay mediación total cuando la obra es representada, esto implica un cambio continuo, pues solo es actual cuando es otra, a la vez que en cada actualización es la misma obra la que se pone ante nuestra mirada. Además, su ser no puede separarse de su representación. Para que realmente exista tal retorno, tiene que estar representándose. En la representación se une el pasado y el presente, y se realiza lo que nuestro autor denomina la simultaneidad de la obra.

Algo similar ocurre en la celebración de una fiesta: la fiesta es una y cada ańo se la celebra de modo diferente. Sin embargo, a pesar del paso del tiempo y de las diferencias que se vayan introduciendo en la celebración, nadie dudaría que la fiesta es solo una: hay un acontecimiento que la funda y que se revive cada ańo. "Las fiestas que retornan no se llaman así porque se les asigne un lugar en el orden del tiempo; antes bien, ocurre lo contrario: el orden del tiempo se origina en la repetición de las fiestas." (GADAMER, 1991, p. 103).

La permanente actualidad de la obra de arte no se debe entonces a que esta esté inserta en una intemporalidad, o a que se desarrolle en un tiempo diferente. Ella es temporal y tiene la marca de la temporalidad radicalmente impresa: la fiesta solo es cuando es radicalmente otra. Solo se valida como fiesta en las diferentes celebraciones. Cuando no se celebra, cuando no es nuevamente otra en la fecha indicada, no hay realmente fiesta. Ahora bien, hay celebración porque la fiesta está allí, porque hay un acontecimiento que la funda. Lo mismo ocurre con la representación de la obra: la obra solo es realmente cuando se la representa, aunque cada vez se la represente de modo diferente. Sin embargo, su ser no es sólo el punto de intersección de todas las representaciones. Su permanente presente se debe a que hay una sola significación en ella, como hay en la fiesta un solo acontecimiento que la funda, ya que solo hay obra de arte en su representación. 
Desde esta perspectiva, la obra de arte, la obra teatral, nos presenta un nuevo desafío: ¿cómo se realizan esas nuevas actualizaciones? ¿Cómo se produce esa perenne presencia de la obra en sus múltiples interpretaciones?

Aquí no se da una coexistencia arbitraria, una simple variedad de acepciones; al contrario, por el hecho de que unas cosas están sirviendo continuamente de modelo a las siguientes, y por las transformaciones productivas de éstas, se forma una tradición con la que tiene que confrontarse cualquier intento nuevo. (GADAMER, 2005, p. 164).

Gadamer trata ampliamente el tema de la tradición. Por ahora, en el tema de la temporalidad, lo que nos interesa es que tal temporalidad implica una cadena de interpretaciones en las cuales hay unas que son más vinculantes que otras, y que se transforman en modelos, hasta tal punto que se identifican con la obra misma y crean una tradición. Esto es parte de la estructura de la comprensión; quien comprende no lo hace desde su autoconciencia pura, desde una actualidad sin influencias precedentes. Toda actualización de sentido de la obra cuenta con las actualizaciones previas y está condicionada por ellas.

\subsection{LA CUESTIÓN DE LA INTERPRETACIÓN DESDE LA OBRA}

Desde la noción de mediación total, la cuestión de la representación nos ha llevado hasta el concepto de interpretación. La mediación que realiza la representación es, por una parte, total, por lo que la dirección intencional lo es hacia la obra misma; y, por otra parte, la mediación produce una distancia óntica respecto a lo representado, al original. La paradoja estriba en que esta desproporción, esta distancia, juega un papel positivo y posibilitador para la esencia de lo representado, que se perfila más nítidamente desde la representación. Esta representación o imitación no es nunca, por tanto, mera copia: es una mostración nueva de la realidad, nueva y enriquecida por la mirada de quien imita - el que interpreta un papel en la obra - y, como veremos a continuación, también por la de quien observa. Desde la línea presentada por Gadamer la mímesis tiene un papel posibilitador. No es imitación, en sentido estricto; no es una mera copia de la realidad ni tampoco las sucesivas versiones de la obra son copias del original. Esta mímesis, ejemplificada en la representación teatral, ocupa un papel intermedio entre el mundo del texto y el espectador, sin disolverse en ninguno de los dos polos. Este intermediario se 
sostiene a sí mismo y re-presenta más bien un desocultamiento de la verdad. Es una re-presentación de la obra que tiene un sentido propio.

Ahora bien, una vez agotado el análisis de la obra de arte teatral, Gadamer nos mostrará que este proceso de mediación es el que sucede siempre que queremos comprender: cuando el lector comprende, interpreta lo que tiene ante sus ojos, y la acción realizada es la misma que la realizada por el actor, como también es la misma que realiza un músico frente a la partitura o un bailarín interpretando una pieza. De hecho, en el lenguaje cotidiano hablamos, en todos estos casos, de interpretación: se interpreta un texto, un papel teatral, una pieza musical. Es más, propiamente hablando, los instrumentos se interpretan, no se tocan simplemente. Esta concepción de la interpretación nos sirve también, por tanto, para todo tipo de obra de arte, no solo para el texto. La referencia es el mundo que la obra presenta, que en el caso de la obra teatral se levanta ante nuestros ojos, como lo hace ante nuestros oídos la obra musical. Ese mundo que se eleva en la lectura que hace el lector, es el mundo que se eleva también en la lectura que hace el actor de la obra, y que se pone en acción en la representación. Ahora bien, el espectador de esta obra hace a su vez una nueva interpretación en tanto participa del sentido de lo representado.

Si bien en el uso común de la palabra interpretación estos modos son tomados como acepciones diferentes, en el contexto actual de nuestro análisis la distinción no es real. ${ }^{2}$ En el caso del actor, hay una comprensión, una experiencia de sentido con el texto, una participación de su sentido, desde la que luego el papel que le corresponde toma cuerpo. En el caso del espectador, hay una comprensión personal de ese papel que ante él se representa. "Por supuesto que mimesis no quiere decir aquí imitar algo previamente conocido, sino llevar algo a su representación, de suerte que esté presente ahí en su plenitud sensible." (GADAMER, 1991, p. 92-93). No hay una doble mímesis en sentido negativo: hay un doble re-presentar, un doble poner de relieve la esencia de la obra, una doble luz sobre tal esencia. Por esto, hay un enriquecimiento del texto o de la obra, pues la inserción en la tradición,

2 Una dificultad que se presenta en la obra de Gadamer es la cuestión de la identificación de la comprensión y la interpretación. Hay momentos en la obra en que identifica ambos conceptos y momentos en que los distingue. Parte del problema estriba en que las nociones básicas que él desarrolla tienen una pluralidad de significados. En la interpretación de Grondin, la comprensión tiene en la obra de Gadamer varios significados: comprensión como "aprehensión intelectual" (intelectual grasp), como "saber hacer práctico" (practical know-how) y como "acuerdo" (agreemento). Esto, para Grondin, no supone una dificultad: "Quite on the contrary, he sees in this plurality of meaning an indication that language, long before thinking, is perhaps up to something essential." (GRONDIN, 2002, p. 36). 
la experiencia de cada uno de los intérpretes, la facticidad en que estos se inscriben, des-cubren nuevos matices a cada interpretación.

Toda comprensión se inscribe en una tradición de interpretaciones. La imagen del espectador ante la obra representada resulta, en este punto, esclarecedora: el espectador no puede tener pretensión de dominio de todos los factores que entran en juego en el sentido de la obra que está conociendo, pues al menos debe aceptar que hay otro del que depende su propia comprensión: el actor. Se descubre aquí un nuevo matiz de la estructura de la comprensión: el espectador, en tanto intérprete, no sólo no puede dominar su objeto, no solo no puede objetivar realmente la realidad por ser ella inabarcable sino también porque su comprensión se inscribe en una dinámica de interpretaciones que no domina objetivamente, en una tradición desde la cual él es capaz de descubrir sentido. Este es el movimiento que grafica lo que sucede en la tradición: cada interpretación es un nuevo eslabón de las sucesivas experiencias de sentido, de las que la nueva interpretación entra a formar parte.

La verdad, por tanto, se muestra cuando hay alguien que se vuelva hacia ella, como un espectador. Este volverse, es el acto de la interpretación. Por la interpretación nos volvemos hacia la verdad de algo, y lo hacemos más eminentemente cuando, abstrayéndonos del entramado causal de la vida cotidiana, accedemos a la realidad misma en busca de su sentido. A esto se refiere Gadamer con la idea de tragedia y comedia de la vida: cuando los sucesos de la vida son mirados desde fuera, cuando se toma distancia de ellos, es decir, cuando se realiza el acto de poner entre paréntesis el conjunto de móviles causales con que operamos en la realidad cotidiana, la misma vida puede transformarse en una experiencia de sentido, en un drama: ella ya no se vive, sino que se exhibe ante nosotros (Darstellung). Supone un detenerse frente a la vida, como frente a la representación o a la obra de arte, para tomar parte, participar de su significado. "Es verdad que la dialéctica del tiempo que transcurre y se consume lo rige todo. $\mathrm{Y}$, sin embargo, cuando alguien comprende, algo queda detenido." (GADAMER, 1998a, p. 155). Solo por esta acción puede haber un acontecer de la verdad. Por eso, para Gadamer la hermenéutica no es sólo el arte de la interpretación de textos ni tampoco una disciplina filosófica que investiga las condiciones por las que tiene lugar la comprensión, sino que su pensamiento se asienta sobre la base de que hermenéutica designa una concepción de la filosofía como tal: la comprensión pasa al centro del interés filosófico. 
Esta radicalización de la perspectiva hermenéutica, que la abre desde el mundo del texto al mundo de la vida. Ahora bien, el paso desde lo que sucede frente a la obra de arte y frente al texto hacia lo que sucede en la comprensión vital es un paso que en Gadamer presenta dificultades. Toda su obra se aboca al análisis del trato con la tradición, y esta entregada en los textos y las obras. La referencia, en cambio, al mundo de la vida es tan escasa en su obra, que deslindar con nitidez cómo media la interpretación, o las prestaciones de carácter interpretativo, en el trato práctico-operativo en el mundo de la vida, en el trato con lo que Heidegger llama entes a la mano, no es fácil. De hecho, hay momentos en que él mismo habla de comprensión directa, y otros en que habla que toda comprensión es mediada por la interpretación. La imagen de la representación teatral tiene, por tanto, sus límites: la obra misma solo puede ser comprendida por la mediación de la interpretación de la representación teatral. Esto implica que el espectador, según hemos dicho, se pone en una actitud de "contemplación", que dista de la actitud cotidiana. Ahora bien, el problema, a fin de cuentas, es que queda en entredicho si hay o no ámbitos de trato directo, no mediado por la interpretación, con el mundo. O si en el trato cotidiano con el mundo hay también mediación interpretativa. Lo que está en juego no es menor, pues es en la posibilidad de dar cuenta del modo como la interpretación media todo ámbito vital, radica la posibilidad de una auténtica ontología hermenéutica. Esta cuestión, seguirá siendo problemática en la obra de Gadamer.

\section{LA TAREA HERMENÉUTICA DESDE LA ONTOLOGÍA DE LA OBRA DE ARTE}

\subsection{LA HISTORICIDAD DE LA COMPRESIÓN}

Una vez desarrollada la ontología de la obra de arte Gadamer está en condiciones de entregar su propia teoría hermenéutica. La cuestión central en el desarrollo de su teoría hermenéutica será el mutuo entrelazamiento entre quien comprende y el mundo que conoce. Por tanto, los factores que hay que considerar al momento de afrontar la cuestión de la comprensión son aquellos que hacen entrar en un juego indisociable al ser humano con el mundo que conoce.

Mucho antes de que nosotros nos comprendamos a nosotros mismos en la reflexión, nos estamos comprendiendo ya de una manera autoevidente en la familia, la sociedad y el estado en que vivimos. La lente de la subjetividad es un espejo deformante. La autorreflexión del individuo no es más que una chispa en la corriente cerrada de la vida histórica. Por eso los prejuicios de un individuo son, mucho más que sus juicios, la realidad histórica de su ser. (GADAMER, 2005, p. 344. Cursiva del autor.). 
La tradición, que se podría definir como esos mismos prejuicios compartidos por una sociedad y materializados en una cultura, es crucial, en tanto condición de posibilidad, para toda comprensión. La tradición, por tanto, no puede, desde esta perspectiva, considerarse de modo objetivo, como algo extraño a quien la estudia, como objeto de aceptación o rechazo, pues estamos insertos dentro de ella, por lo que su estudio es el estudio de nosotros mismos. Tal como la palabra misma lo indica, la tradición es lo que se nos entrega en legado, aquello dado. "La posición entre extrańeza y familiaridad que ocupa para nosotros la tradición es el punto medio entre la objetividad de la distancia histórica y la pertenencia a una tradición. Y este punto medio es el verdadero topos de la hermenéutica." (GADAMER, 2005, p. 365. Cursiva del autor.).

Los clásicos muestran justamente la validación de la autoridad de la tradición, la cual tiene autoridad no por ser tradición consagrada, sino que se consagra como tal porque tiene autoridad. En el ámbito de las artes, sobre todo en la literatura, esta noción tiene una importancia capital. Se erigen en clásicos aquellos textos que por siglos son considerados vinculantes para la cultura. El diálogo intersubjetivo, presente siempre en la cultura, con la consagración de los clásicos muestra su poder, pues erige en modelo para todas las futuras interpretaciones a unas obras determinadas. El diálogo es fundamental para la teoría hermenéutica que Gadamer desarrolla, pues en él se acredita la verdad, el acuerdo. Los clásicos, de alguna manera, acreditan la posibilidad de acuerdo, muestran que es una posibilidad real, a la vez que materializan el juego entre la tradición y la comprensión actual, entre pasado y presente. Pues si bien es cierto que algo que se erige en clásico se vuelve modelo, también lo es el hecho de que cada época actualiza esos clásicos de un modo diferente. El fenómeno de lo clásico,

No designa una cualidad que se atribuya a determinados fenómenos históricos, sino un modo característico del mismo ser histórico, la realización de una conservación que, en una confirmación constantemente renovada, hace posible la existencia de algo que es verdad. (GADAMER, 2005, p. 356).

Por tanto, cada interpretación se inscribe en lo que Gadamer llama historia efectual, que designa los nexos de vigencia de sentido. Es decir, llevando la cuestión nuevamente al campo de las artes, los efectos de los que depende nuestra comprensión no son solo los efectos mecánicos de una puesta 
en escena. Si bien en el caso de las artes procesuales nuestra comprensión depende de la mecánica de la puesta en escena, como de hecho la comprensión de un texto depende del acto de escritura que alguien lleve a cabo, la historia efectual a la que se refiere es más bien a las interpretaciones de la obra. Nuestra comprensión pende de los nexos de sentido que el texto traiga ya arraigado. Como sucede en el caso de los clásicos, ellos portan un cúmulo de sentidos que están vigentes al momento de abrirse a una nueva comprensión. Nuestra propia comprensión se inserta en la historia efectual, depende de ella y pasa a formar parte de ella. Esto hace que, de hecho, la obra o texto sea inobjetivable, pues no se puede objetivar todos los nexos de sentido que influyen en nuestra propia comprensión. "Ser histórico quiere decir no agotarse nunca en el saberse.” (GADAMER, 2005, p. 372).

La ilusión de un punto de partida completamente neutro queda, entonces, derribada, y la autotransparencia de la conciencia se transforma en una utopía, y esto no solo porque aquello que se busca comprender es inabarcable, se presenta como inasible por estar metido en la trama de la historia efectual, sino también porque quien la estudia es parte de lo estudiado mismo, por lo que no puede sustraerse de modo absoluto de la trama de la que forma parte irremediablemente. La posición neutral del sujeto, supuesta en el método científico, es reemplazada por la noción de horizonte, que se abre desde la propia tradición hacia lo comprensible.

El horizonte es más bien algo en lo que hacemos nuestro camino y que hace el camino con nosotros. El horizonte se desplaza al paso de quien se mueve. También el horizonte del pasado, del que vive toda vida humana y que está ahí bajo la forma de la tradición, se encuentra en un perpetuo movimiento. (GADAMER, 2005, p. 375).

La idea de horizonte busca destacar el hecho de que, si la situación en que nos encontramos es siempre situada, nuestra proyección de sentido también lo es. Cada proceso comprensivo comienza desde una situación, desde la que se puede establecer una posición, pero nunca de modo neutral, sino impregnada de esa misma situación: desde ella lo que se abre son perspectivas. Y estas perspectivas no son fijas, sino movibles: cada perspectiva abre posibilidades diversas, y cada actualización de una de esas posibilidades, trae a su vez otra gama de posibilidades. 


\begin{abstract}
"Horizonte" evoca la experiencia viva que todos conocemos. La mirada está dirigida hacia el infinito de la lejanía, y este infinito retrocede ante nosotros con cada esfuerzo, por grande que sea, se abren siempre otros nuevos horizontes. El mundo es en este sentido para nosotros un espacio sin límites en medio del cual estamos y buscamos nuestra modesta orientación. (GADAMER, 1998a, p. 122).
\end{abstract}

En esta continua actualización de sentido, solo algunos proyectos cuajan, y si lo hacen, es porque quedan otras posibilidades abiertas. A la vez, cada actualización que cristaliza en una interpretación condiciona las siguientes interpretaciones, como veíamos en el caso de los clásicos: esta es la movilidad a la que se refiere Gadamer. Y esta dinámica de actualización de la tradición se materializa, se muestra de manera gráfica, en la tarea de la traducción. Ahora bien, es fundamental comprender que estos horizontes movibles no dependen solo de las perspectivas futuras de realización, sino también del pasado: para que realmente exista una comprensión del pasado entregado en la tradición es necesario comprender los conceptos desde los que habla, y hacerlos propios desde los conceptos actuales. "La experiencia hermenéutica no consiste en que algo esté fuera y tienda a entrar dentro. Más bien, somos captados por algo; y justamente en virtud de lo que nos capta y posee, estamos abiertos a lo nuevo, a lo distinto, a lo verdadero". (GADAMER, 1998b, p.218). A la vez, ninguno de estos horizontes desde los cuales se traza la comprensión es cerrado: hay un constante alimentarse unos de otros: "Comprender es siempre el proceso de fusión de estos presuntos 'horizontes para sí mismos”. (GADAMER, 2005, p. 376-377).

Ahora bien, en esta dinámica de apropiación que se produce en el diálogo con la tradición, tiene consecuencias ónticas, según vimos. En el análisis de la obra, Gadamer afirma que la interpretación o representación de la misma produce un incremento de ser de lo representado:

Cada representación viene a ser un proceso óntico que contribuye a constituir el rango óntico de lo representado. La representación supone para ello un incremento de ser (Zuwachs an Sein). El contenido propio de la imagen determina ontológicamente como emanación de la imagen original. (GADAMER, 2005, p. 189). 
Esto implicaría que, si damos el paso de la noción de representación a la de interpretación, cada apropiación de lo entregado en la tradición implicaría un incremento de ser. La cuestión que queda en entredicho, y que se sigue de la ya comentada problemática del cómo median las prestaciones interpretativas en el "mundo de la vida", es el alcance dichas consecuencias ónticas. Este incremento de ser se puede interpretar como un incremento de manifestabilidad, es decir, como la posibilidad misma de que el ser se fenomenalice para nosotros en la comprensión, entendida como interpretación. $\mathrm{O}$ bien se puede leer como afirmación de que la interpretación, que se realiza en el medio del lenguaje, crea mundo. Esta última es la interpretación que hace, entro otros, Vattimo, quien afirma que, si las premisas de Gadamer se llevan hasta las últimas consecuencias, se tiene que aceptar la idea de que el leguaje crea, en sentido fuerte, la realidad. Afirma Vattimo (2003, p. 61):

Precisamente en la identificación entre interpretar el mundo y transformarlo (actuando históricamente) así como, sobre todo, en la identificación de comprenderse y ser sí mismos por parte de los agentes que así actúan reside, probablemente, uno de los núcleos, si es que no la tesis nuclear, de la hermenéutica de Gadamer.

Ahora bien, la lectura de Vattimo no nos parece coherente son las ideas hasta ahora desplegadas en este trabajo. Y esto porque la noción de mediación de la interpretación o representación de la obra y la necesidad de la vinculatividad de dicha mediación con la obra, así como la noción de lo clásico, no nos parece que permitan una lectura como la que propone este autor.

En esta misma línea, otra cuestión problemática que cabe aclarar llegados a este punto es el alcance de la superación del paradigma sujeto/ objeto. Esto porque, a pesar de la caracterización que realiza Gadamer a través de la imagen del juego, en donde el jugador debe "dejarse llevar por el juego", y en el que la voz de la tradición cobra un papel central, es indudable que está asumiendo que el jugador, el intérprete, realiza una acción propia. De hecho, la interpretación es para nuestro autor una apropiación de la tradición. En este sentido, afirmar que en Gadamer existe un anti-subjetivismo, nos parece erróneo. Como afirma Theunissen (2003, p. 82-83):

La conexión producida por el concepto de sujeto solo hace el efecto de estar construida porque con la interpretación el arte como juego sin jugadores se toma ya de antemano una decisión previa y contraintuitiva acerca del lenguaje. Solo que Gadamer, - y esto es lo único que cuenta aquí - no toma ninguna disposición para transferir su interpretament 
del arte y del lenguaje a la comprensión. Esto sería incluso ilícito, pues para él, el comprender no puede ser sin sujeto. De otro modo, enseñanzas fundamentales, como su teorema de la fusión de horizontes, se quedarían colgados. No se puede negar que él sombre, y con razón, en un sentido determinado, la subjetividad extraña. A saber, en tanto creadora de una obra por comprender. La subjetividad propia de cada cual, en cambio, la del que comprende, no la ha hecho valer nadie en la historia del pensamiento hermenéutico tanto como él.

Así como la tesis del anti-subjetivismo no parece sostenerse, en esta misma línea, la idea de que no haya ningún tipo de "objetividad", o de algo externo a la interpretación que haga de baremo de corrección de dicha interpretación, no parece plausible.

\subsection{LA EXPERIENCIA HERMENÉUTICA}

Ahora bien, el hecho de que el intérprete se haga consciente de que cada interpretación sea una cristalización de posibilidades que se abren desde los efectos que una obra porta consigo, a la vez que desde esa cristalización se abre a un nuevo proyecto, no quiere decir que la interpretación se reduzca a ser el punto de convergencia de los efectos de interpretaciones precedentes. Lo que sucede frente a la obra es una verdadera experiencia; es decir, la estructura del acto de interpretación, aun cuando ese acto se realice desde la toma de conciencia de la situación hermenéutica, es la del encuentro con un acontecer particular, nuevo, que debe hacerse propio. "Esto es exactamente lo que importa retener para el análisis de la conciencia de la historia efectual: que tiene la estructura de la experiencia." (GADAMER, 2005, p. 421). Lo primero para entender este concepto es liberarlo de las estrecheces en las que los ha encajado la metodología científica, que lo ha determinado de manera que pueda hacer uso de él: una experiencia es algo que, desligado de su particularidad, se convierte en un caso de la generalidad, se esquematiza en pos de la generalidad a la que quiere servir como prueba. De este modo, queda garantizada la objetividad, y cada caso, cada experiencia, muy lejos de ser única, se transforma en reproducible, desentendiéndose de los factores históricos que la determinan esencialmente. Esta desconexión de su realidad histórica, realidad que, de hecho, es condición de su realización, hace de tal experiencia un caso que comprueba la ley, a la que apunta la teoría científica.

Lo que intentará Gadamer es recuperar la noción de experiencia para poder, a partir de ella, describir la experiencia hermenéutica. Lo primero, 
por tanto, es descubrir qué es lo que tiene en común toda experiencia, sea o no erigida posteriormente en un caso de una ley. "La experiencia solo se da de manera actual en las observaciones individuales. No se la sabe en una generalidad precedente". (GADAMER, 2005, p. 427).

Toda experiencia, por tanto, implica novedad. En este sentido, cada experiencia es única. Sin embargo, a la vez que cada una es única, hay un momento de generalidad. Tanto en la experiencia científica como en la experiencia vital o cotidiana, hay una generalidad que posibilita la previsión, una unidad que proviene de un elemento común que lleva a poder calificar a una serie de acontecimientos desde la misma experiencia. La ciencia nace de la búsqueda de las causas de esos elementos comunes, que llevan a denominar variadas experiencias bajo un mismo concepto.

Ahora bien, toda experiencia es válida en cuanto no es refutada por una nueva experiencia. En el caso de la ciencia, de eso depende la validez de una teoría; en el caso de la experiencia vital, la refutación de la experiencia previa por una nueva situación, lleva a fundar una nueva experiencia. La cuestión que diferencia a la experiencia vital de la científica es que esta última busca la generalidad de la experiencia como medio para el avance de su investigación, y para eso tiene que desconectar todo carácter particular de las distintas experiencias, todo momento histórico: lo que le interesa de aquellos acontecimientos es únicamente lo que tienen en común, que será lo que luego se conceptualizará científicamente en una teoría. En cambio, en la experiencia cotidiana lo vinculante es la inserción en la historicidad, los elementos que diferencian un caso de otro, pues esos elementos son los que realizan la verdadera experiencia. Por esto, otra diferencia estriba en el valor que cobra la refutación de las expectativas que provoca la generalidad de la experiencia en la ciencia y en la vida. En el primer caso, lo que se busca es que las expectativas sean corroboradas, para que la ley se verifique. En el caso de la experiencia cotidiana, no hay tal fin. De hecho, no se busca fin alguno. Las experiencias, en este caso, no se buscan, sino que suceden. De esta sucesión de acontecimientos se obtendrán generalidades, pero también, y esto es lo más enriquecedor y más definitivo, estas generalidades serán decepcionadas.

Y cuando se considera la experiencia solo por referencia a su resultado se pasa por encima del verdadero proceso de la experiencia; pues éste es esencialmente negativo. No se lo puede describir simplemente como la formación, sin rupturas, de generalidades típicas. Esta formación ocurre más bien porque generalizaciones falsas son constantemente refutadas por la experiencia, y cosas tenidas por típicas han de ser destipificadas. Esto tiene su reflejo lingüístico en el hecho de que hablamos de experiencia en 
un doble sentido, por una parte, como las experiencias que se integran en nuestras expectativas y las confirman, por la otra como la experiencia que se "hace". (GADAMER, 2005, p. 428).

Es la distancia respecto de la expectativa, que en la obra graficábamos como la distancia o desproporción óntica de lo representado respecto del texto. Cuando una experiencia desarticula la experiencia previa, cuando lleva al derrumbe de lo anterior, esto "Contiene siempre un retornar desde la posición que uno había adoptado por ceguera. En este sentido implica siempre un momento de autoconocimiento y representa un aspecto necesario de lo que llamábamos experiencia en sentido auténtico". (GADAMER, 2005, p. 432). De este modo, el auténtico aprendizaje que proviene de esta experiencia es la apertura hacia las nuevas experiencias. Cuando descubrimos que lo que nos parecía ser conocimiento adquirido no se sostiene, es refutado por una nueva experiencia, lo que se produce es la apertura, que tiene la estructura del diálogo.

Desde esta perspectiva, la diferencia entre la experiencia vital y la científica es radical: el científico posee una teoría gracias a las sucesivas experiencias que la corroboran; él tiene un dominio de saber; de ahí la posibilidad de la técnica. Muy diferente es la situación de quien tiene experiencia de la vida: él sabe que no domina nada, pues las sucesivas experiencias le han abierto los ojos para descubrir la propia limitación, y saber que no hay experiencia definitiva; por lo tanto, la única actitud válida frente a estas experiencias es la apertura, que proviene del derrumbe del dogmatismo. De hecho, la admiración, principio de la filosofía, es consecuencia del derrumbe de las expectativas.

Una vez descritas las características de la experiencia, podemos responder qué es la experiencia hermenéutica.

La experiencia hermenéutica tiene que ver con la tradición. Es esta la que tiene que acceder a la experiencia. Sin embargo, la tradición no es un simple acontecer que pudiera conocerse y dominarse por la experiencia, sino que es lenguaje, esto es, habla por sí misma como lo hace un tú. El tú no es objeto, sino que se comporta respecto a objetos. Pero esto no debe malinterpretarse como si en la tradición lo que en ella accede a la experiencia se comprendiese como la opinión de otro que es a la vez un tú. Por el contrario, estamos convencidos de que la comprensión de la tradición no entiende el texto transmitido como la manifestación vital de un tú, sino como un contenido de sentido libre de toda atadura. (GADAMER, 2005, p. 434). 
La clave de la cuestión hermenéutica está, por tanto, en la consideración dialógica del trato con la tradición: ella habla como un tú. Por lo tanto, la tarea de quien quiere dialogar con la tradición se convierte en una tarea moral: el trato con la tradición, así como el trato con otra persona, que se entrega en el lenguaje, ya no es una cuestión metodológica, pues no se puede pretender un conocimiento objetivo del otro con quien se dialoga. Por tanto, la experiencia hermenéutica es este diálogo con la tradición, en el que quien comprende se entrega, y que tiene la estructura de toda experiencia vital: la experiencia de la participación en una generalidad, participación que posibilita la comprensión, pero que a la vez se ve derrumbada por una nueva experiencia, en tanto hay un desajuste de expectativas, una distancia, generando así una conciencia histórica que tiene como núcleo la experiencia de la propia finitud. Esta experiencia es desconocida para la pretensión de una verdad objetiva, que sea consecuencia de un método.

Siguiendo el análisis de la cuestión problemática que hemos visto respecto de la mediación interpretativa en el mundo de la vida, la noción la experiencia, tal como se ha planteado, suscita también un problema y muestra sus límites como modelo de la experiencia interpretativa, como vimos que tenía el modelo de la obra teatral. Y esto porque, tal como la caracteriza Gadamer - como momento particular presente en el que se produce un desencaje entre las prestaciones interpretativas proveídas por la tradición y la capacidad de esas mismas prestaciones tienen de cara a la interpretación de la novedad de la situación presente - implica un momento de interrupción del flujo de la vida misma. Es decir, la experiencia interpretativa implica una toma de distancia con la vida misma, con el cotidiano trato con el mundo de la vida. Y en este sentido, no es una experiencia vital entendida como experiencia cotidiana, sino una experiencia vital entendida como momento de aporía vital. En este sentido, el mundo, que ha sido la noción que hemos visto se problematiza a lo largo de la obra gadameriana, no debe ser entendido como mundo cotidiano, sino como aquello que se deja interpretar gracias a esa misma toma de distancia de lo cotidiano, y que, en esa distancia, cobra su sentido propio. Como afirma Figal (2003, p. 113):

[...] a él, el mundo de la vida no le interesa como contexto no objetual de la acción, como condición - casi siempre sin tematizar - del conocimiento científico, sino como algo que puede experimentarse y articularse, que puede representarse y, de este modo, mediarse. Esta mediación es irrenunciable, pues solo en ella tiene el mundo un sentido; el mundo 
tiene que ser representado para que se muestre como espacio de juego y conexión que hace posible y soporta el comportarse en él.

\section{Consideraciones Finales}

La primera condición, por tanto, para la comprensión de la tradición es, evidentemente, la apertura al diálogo. Esta apertura, tal como lo hemos visto, es esencial a la experiencia vital, que nos hace conscientes de nuestro límite, y nos abre a otras perspectivas. Es decir, si hemos visto que la experiencia hermenéutica es como la experiencia vital, esta requiere, a la vez que produce, la apertura. Frente a la distancia que significa la refutación de la expectativa, la primacía en este diálogo la tiene la pregunta: tal distancia, provocada por la frustración de una expectativa, engendra la pregunta "Por eso también el preguntar es más un padecer que un hacer. La pregunta impone; llega un momento en que ella no se la puede seguir eludiendo ni permanecer en la opinión acostumbrada”. (GADAMER, 2005, p. 444).

Por una parte, la tradición es de antemano una respuesta, pero provoca, necesariamente, una pregunta al intérprete, que solo a condición de sentirse cuestionado, entra en diálogo verdadero con la tradición. La pregunta no es nunca una pregunta meramente retórica, como la que hace quien ya sabe la respuesta. Tampoco es la pregunta guiada por una respuesta previamente concebida que pone a prueba lo cuestionado, como sucede en la ciencia, sino que es la pregunta abierta por la frustración de las ideas preconcebidas. Por otra parte, "Con la pregunta lo preguntado es colocado bajo una determinada perspectiva. El que surja una pregunta supone siempre introducir una cierta ruptura con el ser de lo preguntado." (GADAMER, 2005, p. 439). De este modo, la pregunta pone de manifiesto la cuestionabilidad de lo preguntado. Es la tradición la que suscita las preguntas, y en este sentido es la que incita a pensarla desde ella misma, pues no podemos olvidar que el intérprete pertenece a esa misma tradición que lo interpela. En este sentido, la pregunta que se suscita es parte del proceso de hacer propio lo extraño que está latente en esa substancia previa, que nos es también propia, en tanto nos es familiar. Ahora bien, la pregunta que se le hace a la tradición es una entre las muchas que se le puede hacer, pero una vez que se plantea, abre una perspectiva ineludible, pero no única, tal como veíamos al hablar de la fusión de horizontes. La ganancia del horizonte hermenéutico es la capacidad de apertura desde la propia situación, particular, pues solo desde ella se puede proyectar un sentido. Y, como ya hemos visto, la situación es siempre condicionada por la historia efectual, por 
los sentidos vigentes al momento de actualizar la comprensión de un texto, o de un hecho histórico, sentidos que son efectos de interpretaciones previas, y de los que no nos podemos sustraer. Solo desde ellas podemos participar en una nueva interpretación.

Desde la perspectiva de la comprensión como un momento de la historia efectual, la tarea de la comprensión de la tradición tiene en el momento particular de la actualización su verdadera realización, pues solo en ella se realiza la mediación del pasado, con su carga efectual, con el presente; solo en ella se integra el texto en cuestión en el acontecer de la historia efectual, y esa nueva actualización se transforma en una nueva perspectiva, en un nuevo horizonte desde el cual proyectar sentido. Solo en ella se realiza, por tanto, la verdad como Darstellung.

La dialéctica entre la experiencia particular y la generalidad a la que apunta la tarea hermenéutica se realiza en el momento mismo del cuestionamiento de la tradición. Ahora bien, como hemos visto, ese presupuesto común es condición de posibilidad no solo de la pregunta, sino también de la respuesta desde la que se abre un nuevo horizonte de sentido, pues posibilita, desde las interpretaciones previas cuajadas en la tradición, una orientación hacia la respuesta, que se consolida, en tanto es validada por los intérpretes, como un nuevo horizonte, como sucede cuando alguna de esas interpretaciones se convierte en un clásico. Para Gadamer, este horizonte que bebe de la tradición pero que a la vez es movible, es la realización misma del lenguaje. "[...] esta fusión de horizontes que tiene lugar en la comprensión es el rendimiento genuino del lenguaje." (GADAMER, 2005, p. 456).

Tal como hemos visto al analizar los núcleos problemáticos del pensamiento de Gadamer, la frase "el ser que puede ser comprendido es leguaje" debe entenderse, por tanto, en términos de la comprensión como interpretación mediadora entre el ser humano y el mundo. La noción de mundo hace referencia, según vimos, a un todo de sentido al que el ser humano accede desde la mediación interpretativa que es posibilitada por la distancia interpretativa, por la detención que produce la aporía, la frustración de la expectativa que nos saca de la cotidianidad de ese mismo trato con en el mundo. Desde esta interpretación de la noción de mundo, éste puede ser mentado como separado del ser humano, a pesar de que haya un permanente ir y venir de uno a otro, vaivén que es como el juego, pues condiciona la comprensión de ambos: cuando el mundo se manifiesta en la obra, se abre de un modo nuevo, se comprende con luces nuevas y eso influye en quien lo ha comprendido, pero esa comprensión 
no hace, en términos absolutos, mundo, aunque el horizonte interpretativo de aquello que llamamos mundo, cambia. Y esto, justamente por el hecho de que Gadamer parte de la comprensión temática, del como apofántico. Por tanto, como afirma Theunissen (2003), en Gadamer hay una hermeneutización de la ontología, más que una ontologización de la hermenéutica.

BARROS, M. R. G Comprehension as particiation: a dialectic between particularity and generality in GADAMER's hermeneutics. Trans/form/ação, Marília, v. 44, n. 1, p. 265-288, Jan./Mar., 2021.

\begin{abstract}
This article intends to expose the gadamerian's notion of comprehension as participation, aiming to explore the meaning of individual and particularity experiences in relation to understanding the game of this experience with the claim of generality, assumed in the fact that all interpretation belongs to a tradition. From the perspective obtained by the ontology of the work of art, specifically the play of theatrical art, this article will investigate the central notions of Gadamer's philosophical hermeneutics. In first place, the notions of representation and mediation, crucial to understand what is comprehension for our author. In second place, the problem of the temporality of representation will be presented in order to, in third place, state what means interpretation, in its own sense, in gadamerian hermeneutics. Finally, the question of historicity of the hermeneutical task will be developed, because in that task the particularity and generality concur.
\end{abstract}

Keywords: Comprehension. Participation. Interpretation. Work of art. Representation. Temporality. Historicity.

\title{
REFERENCIAS
}

FIGAL, G. Fenomenología de la cultura. Verdad y método después de 40 años In: El ser que puede ser comprendido es lenguaje: homenaje a Hans Georg Gadamer, Madrid: Síntesis, 2003. p 109-116.

GADAMER, H. G. La actualidad de lo bello: el arte como juego, símbolo y fiesta. Barcelona [etc.]: Paidós, ICE de la Universidad Autónoma de Barcelona, 1991.

GADAMER, H. G. Arte y verdad de la palabra. Barcelona: Paidós, 1998a.

GADAMER, HG. Verdad y Método II. Salamanca: Sígueme, 1998b.

GADAMER, HG. Verdad y Método I. Salamanca: Sígueme, 2005.

GADAMER, HG. Estética y hermenéutica. Madrid: Tecnos, 2011. 
GRONDIN, J. Gadamer's basic Understanding of Understanding. In: DOSTAL, Robert (ed.). The Cambridge Companion to Gadamer. Cambridge University Press, 2002. p. 36-51.

GRONDIN, J. Introducción a Gadamer. Barcelona: Herder, 2003.

THEUNISSEN, T. La hermenéutica filosófica como fenomenología del apropiamiento de la tradición. In: El ser que puede ser comprendido es lenguaje: homenaje a Hans Georg Gadamer, Madrid: Síntesis, 2003. p. 71-96.

VATTIMO, G. Comprender el mundo, transformar el mundo. In: El ser que puede ser comprendido es lenguaje: homenaje a Hans Georg Gadamer, Madrid: Síntesis, 2003. p. 59-70.

Recebido: 1/01/2020

Aceito: 30/4/2020 